\title{
Polymeric cantilever-based biosensors with integrated readout
}

\author{
Johansson, Alicia; Blagoi, Gabriela; Boisen, Anja
}

Published in:

Applied Physics Letters

Link to article, DOI:

$10.1063 / 1.2364843$

Publication date:

2006

Document Version

Publisher's PDF, also known as Version of record

Link back to DTU Orbit

Citation (APA):

Johansson, A., Blagoi, G., \& Boisen, A. (2006). Polymeric cantilever-based biosensors with integrated readout. Applied Physics Letters, 89(17), 173505. https://doi.org/10.1063/1.2364843

\section{General rights}

Copyright and moral rights for the publications made accessible in the public portal are retained by the authors and/or other copyright owners and it is a condition of accessing publications that users recognise and abide by the legal requirements associated with these rights.

- Users may download and print one copy of any publication from the public portal for the purpose of private study or research.

- You may not further distribute the material or use it for any profit-making activity or commercial gain

- You may freely distribute the URL identifying the publication in the public portal

If you believe that this document breaches copyright please contact us providing details, and we will remove access to the work immediately and investigate your claim. 


\title{
Polymeric cantilever-based biosensors with integrated readout
}

\author{
Alicia Johansson, ${ }^{\text {a) }}$ Gabriela Blagoi, and Anja Boisen \\ Department of Micro and Nanotechnology (MIC), Technical University of Denmark (DTU), \\ Build. 345 East, 2800 Kgs. Lyngby, Denmark
}

(Received 17 July 2006; accepted 7 September 2006; published online 25 October 2006)

\begin{abstract}
The authors present an SU-8 cantilever chip with integrated piezoresistors for detection of surface stress changes due to adsorption of biomolecules on the cantilever surface. Mercaptohexanol is used as a model biomolecule to study molecular interactions with Au-coated SU-8 cantilevers and surface stress changes of about $0.1 \mathrm{~N} / \mathrm{m}$ are observed. The measurements indicate that the SU-8 surface is inert to mercaptohexanol molecules, which enables the use of a bare SU-8 cantilever as a reference. Moreover, the sensitivity of the cantilevers to $p \mathrm{H}$ changes is presented. The results demonstrate that SU-8 cantilevers are a promising alternative to Si-based cantilevers. (C) 2006 American Institute of Physics. [DOI: 10.1063/1.2364843]
\end{abstract}

The photosensitive epoxy-based polymer SU-8 is becoming widely used for all kinds of micromechanical and microfluidic devices not only as a photoresist but also as the constitutional material of the device. We have developed a cantilever sensor fabricated in SU-8 where the readout is an integrated strain sensor made of Au. ${ }^{1}$ Cantilever sensors can be used for label-free biochemical detection, when the cantilever is functionalized with a sensing layer that interacts with the target biomolecule, ${ }^{2}$ see Fig. 1. Label-free detection of $\mathrm{DNA}^{4}$ and proteins ${ }^{5}$ has been demonstrated using cantilever-based sensors. Due to the micrometer-sized cantilever, this technique allows for high sensitivity measurements with low reagent consumption. Conventionally, cantilevers are fabricated in Si-based materials but due to the low Young modulus of SU-8, cantilevers made in SU-8 have even better sensitivity. Moreover, SU-8 has excellent chemical resistance and the fabrication of the chips is much faster and requires less equipment compared to $\mathrm{Si}$ processing. This makes the final device cheaper than conventional Si-based sensors. Surface stress measurements have been demonstrated using polymer-based cantilevers for optical readout, such as SU-8 cantilevers ${ }^{6}$ and laser machined polyethylene terephthalate cantilevers. ${ }^{7}$ Here, we present an SU-8-based cantilever chip with integrated Au piezoresistors for readout. By using integrated electrical readout, instead of optical readout, the sensor device can be made more compact. We have previously demonstrated measurements in gas phase using these SU-8 cantilevers and here we present results from measurements in liquid phase. ${ }^{1}$

The SU-8 chip has four micrometer-sized cantilevers placed in a channel structure. The chips are fabricated in SU-8 2002 and 2075 (MicroChem Corp.) on a Si wafer and are released after fabrication. The cantilevers are $280 \mu \mathrm{m}$ wide, $215 \mu \mathrm{m}$ long, and about $3.5 \mu \mathrm{m}$ thick, see Fig. 2. The thickness of the Au used for the piezoresistors is $600 \AA$ and the resistance of the piezoresistor is approximately $500 \Omega$. The SU-8 chip is mounted on a printed circuit board and the electrical interconnection is achieved either by flip-chip bonding or by using silver paste. ${ }^{8}$ A small microfluidic system, where tubes can be easily and reversibly attached, has

${ }^{a)}$ Electronic mail: aj@mic.dtu.dk been fabricated in polymethyl methacrylate and polydimethylsiloxane (PDMS) by micromilling.

Interaction of molecules on one side of the cantilever induces a bending of the cantilever which results in a resistance change $(\Delta R)$ in the integrated piezoresistor. To minimize the noise and drift of the output signal, the resistors are connected in a Wheatstone bridge configuration and a reference cantilever is used for all measurements. The change in surface stress $\Delta \sigma_{s}$ can be expressed as $\Delta \sigma_{s}=A \Delta V_{\text {out }} / V_{\text {in }}$, where $V_{\text {out }}$ is the output voltage from the Wheatstone bridge and $V_{\text {in }}$ is the input voltage. $A$ is a constant which depends on the surface stress sensitivity of the cantilever which in turn depends on the geometry of the cantilever, the gauge factor of the piezoresistor, and Young's modulus and Poisson's ratio of the cantilever materials. ' Young's modulus of SU-8 is about $3.5 \mathrm{GPa}$ and for $\mathrm{Au}$ it is $78 \mathrm{GPa}$. Poisson's ratios for SU- 8 and Au are 0.22 and 0.42 , respectively. For a $3.5 \mu \mathrm{m}$ thick cantilever with a $200 \AA$ thick Au coating, $A=1$ $\times 10^{4} \mathrm{~N} / \mathrm{m}$. Using an input voltage of $0.5 \mathrm{~V}$, a change in output voltage of $1 \mu \mathrm{V}$ corresponds to a surface stress change of $20 \mathrm{mN} / \mathrm{m}$. The sensitivity of the SU-8 cantilever is about the same as for Si-based cantilevers with integrated readout.

The surface stress sensitivity of the cantilevers in liquid is characterized by chemisorption of thiols on Au-coated cantilevers. The measuring cantilever is covered with an evaporated $\mathrm{Ti} / \mathrm{Au}$ layer with a thickness of 20/200 $\AA$ while the reference cantilever is left uncoated. Before the chips are used, they are cleaned in a commercial UV/ozone system

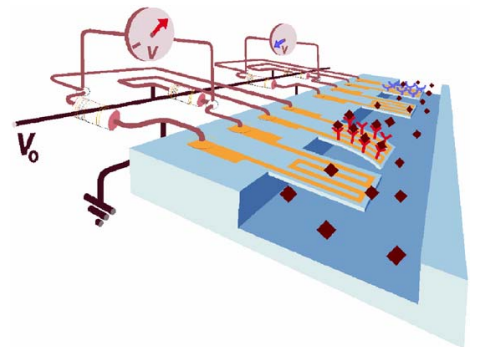

FIG. 1. (Color online) Schematic drawing of a microfluidic channel and four cantilevers made from SU-8. ${ }^{3}$ The binding of analyte molecules results in a bending of the cantilevers which is detected as a change in the resistance of the integrated piezoresistor. One of the cantilevers is always used as a reference. 


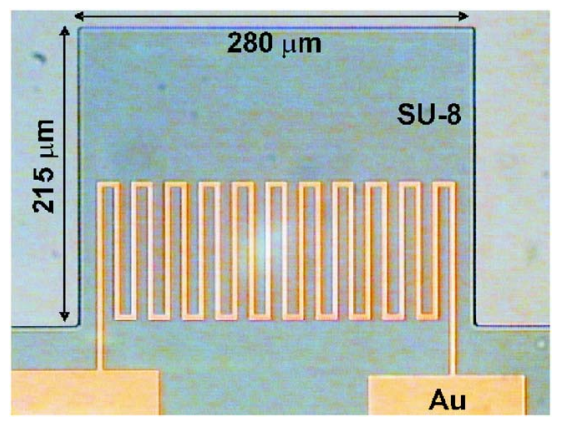

FIG. 2. (Color online) Optical microscope image of an SU-8 cantilever with an integrated Au piezoresistor. Except for the Au resistors, the chip is fabricated entirely from SU-8. The resistors have a resistance of about $500 \Omega$.

(PR 100, UVP Inc.) for 30 min to remove contamination. Contact angle measurements show that Au surfaces become very hydrophilic after $10 \mathrm{~min}$ of UV/ozone treatment which indicates that contaminants are removed. The same is observed for Au surfaces with immobilized thiols which indicates that the chips can be reused after the UV/ozone treatment. 6-mercapto-1-hexanol $\left(\mathrm{SH}-\mathrm{C}_{6} \mathrm{H}_{12}-\mathrm{OH}\right)(\mathrm{MCH})$ is dissolved in MilliQ and is injected into the chamber at a pump rate of $10 \mu \mathrm{l} / \mathrm{min}$. As seen in Fig. 3, the resulting surface stress increases from about 0.06 to $0.16 \mathrm{~N} / \mathrm{m}$ when the thiol concentration increases from 0.2 to $0.5 \mathrm{mM}$. For a concentration of $1 \mathrm{mM}$ the surface stress change is about $0.24 \mathrm{~N} / \mathrm{m}$. The results are comparable to previously reported surface stress measurements using alkanethiols. ${ }^{10}$

To investigate if there are any unspecific interactions between the $\mathrm{MCH}$ and the $\mathrm{Au}$ or SU-8 surfaces, hexanol $\left(\mathrm{C}_{6} \mathrm{H}_{13}-\mathrm{OH}\right)$ is also injected into the microfluidic system. Since hexanol does not have a thiol group it should not chemisorb on the Au surface. As expected, basically no cantilever response is observed when hexanol is injected. This also indicates that there are no interactions between the thiol molecules and the SU-8 surface. To further verify this, $\mathrm{MCH}$ measurements are also done where the reference cantilever is coated with $150 \AA \mathrm{Ti}$ to have an inert top surface of the reference cantilever. The measurements result in about the same voltage change as for an uncoated reference cantilever which suggests that an uncoated SU-8 cantilever is a good

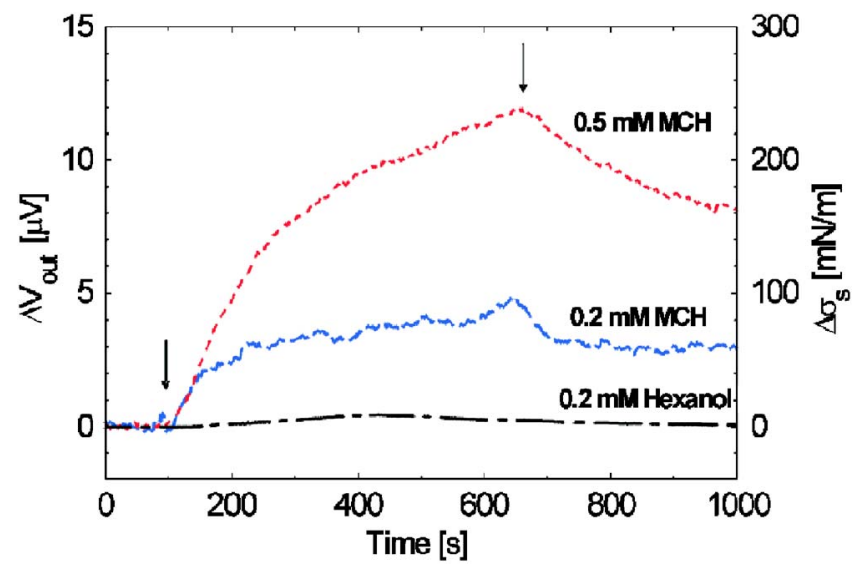

FIG. 3. (Color online) Surface stress measurements of chemisorption of mercaptohexanol on Au-coated SU-8 cantilevers. The arrows show when the sample is introduced and when the valve is switched back to pure MilliQ water again. The signal amplitude is reduced when washing, indicating that some of the molecules are not chemisorbed on the surface and can be

washed off.
Downloaded 17 Jun 2010 to 192.38.67.112. Redistribution subject to AlP license or copyright; see http://apl.aip.org/apl/copyright.jsp

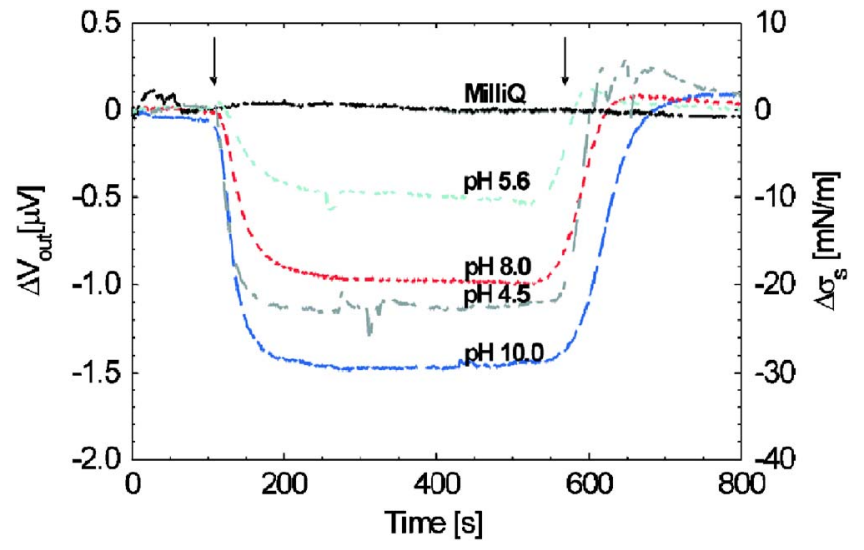

FIG. 4. (Color online) Bending response of Au-coated SU-8 cantilevers as a function of $p \mathrm{H}$. The cantilevers are observed to bend towards the Au surface for both increasing and decreasing $p \mathrm{H}$ values. A bare $\mathrm{SU}-8$ cantilever is used as a reference.

reference cantilever. This makes the thiol experiments simple since no blocking of the SU-8 surface is required. This is an advantage over Si-based cantilevers where unspecific interactions with the thiol molecules are often observed.

To better understand the properties of the SU- 8 cantilevers and their response to chemical stimuli, the influence of $p \mathrm{H}$ on the Au-coated SU-8 cantilevers is also investigated. Freshly made solutions of varying concentrations of $\mathrm{HCl}$ and $\mathrm{NaOH}$ in MilliQ water are used for the measurements. When the solution is switched back to MilliQ the cantilever returns to its initial position, see Fig. 4. The cantilever bends towards the $\mathrm{Au}$ side for both increasing and decreasing $p \mathrm{H}$ values. Similar behavior has been observed for Au-coated $\mathrm{SiO}_{2}$ cantilevers. ${ }^{11}$ The deflection of the cantilever can be due to both $\mathrm{Cl}^{-}$ions interacting with the Au layer and $\mathrm{OH}^{-}$ groups interacting with the SU-8 surface. The observed surface stress changes are comparable to results obtained using SU-8 cantilevers with optical readout which demonstrate that SU-8 cantilevers are less sensitive to $p \mathrm{H}$ changes than Sibased cantilevers. ${ }^{6}$ This is an advantage since it will reduce the influence of changes in ion concentration on the resulting output signal from the molecular recognition event. The reproducibility of the $p \mathrm{H}$ measurements is considerably better than for the $\mathrm{MCH}$ measurements. which suggests that the chemisoption on the Au surface is more difficult to control. Using the same chip and the same concentration, the $\mathrm{MCH}$ measurements can differ by more than a factor of 2 while the $p \mathrm{H}$ measurements differ by less than $5 \%$.

One possibility is that the Au surface is contaminated by silicones from the PDMS in the microfluidic system. ${ }^{12}$

In conclusion, SU-8 cantilever chips with integrated piezoresistive readout and a microfluidic system are presented. The device is characterized by measuring the response to $p \mathrm{H}$ changes and chemisorption of $\mathrm{MCH}$ molecules. The results demonstrate that SU-8 cantilevers can be used for detecting small surface stress changes in liquid. This makes the SU-8 cantilevers more attractive since they have a number of advantages compared to Si-based cantilevers such as being less expensive and easier to fabricate. Moreover, by using integrated readout as presented here, a compact device that is straightforward to use is accomplished. The sensitivity of the cantilevers might be further improved by making the cantilevers thinner, by using a piezoresistor material with a higher gauge factor, or by removing the top Au coating and instead AlP license or copyright; see http://apl.aip.org/apl/copyright.jsp 
immobilizing receptors for biomolecules directly on the SU-8 surface. This is currently under investigation.

The authors would like to acknowledge the Danish innovation consortium MiNap for funding.

\footnotetext{
${ }^{1}$ A. Johansson, M. Calleja, P. A. Rasmussen, and A. Boisen, Sens. Actuators, A, 123-124, 111 (2005).

${ }^{2}$ N. V. Lavrik, M. J. Sepaniak, and P. G. Datskos, Rev. Sci. Instrum. 75, 2229 (2004).

${ }^{3}$ Image by Daniel Häfliger.

${ }^{4}$ R. Mukhopadhyay, M. Lorentzen, J. Kjems, and F. Besenbacher, Langmuir 21, 8400 (2005).

${ }^{5}$ Y. Arntz, J. D. Seeling, H. P. Lang, J. Zhang, P. Hunziker, J. P. Ramseyer,
}

E. Meyer, M. Hegner, and Ch. Gerber, Nanotechnology 14, 86 (2003).

${ }^{6}$ M. Calleja, J. Tamayo, M. Nordström, and A. Boisen, Appl. Phys. Lett. 88, 113901 (2006).

${ }^{7}$ X. R. Zhang and X. Xu, Appl. Phys. Lett. 85, 2423 (2004).

${ }^{8}$ A. Johansson, J. Janting, P. Schultz, K. Hoppe, I. N. Hansen, and A. Boisen, J. Micromech. Microeng. 16, 314 (2006).

${ }^{9}$ P. A. Rasmussen, J. Thaysen, O. Hansen, S. C. Eriksen, and A. Boisen, Ultramicroscopy 97, 371 (2003).

${ }^{10}$ R. Berger, E. Delamarche, H. P. Lang, Ch. Gerber, J. K. Gimzewski, and H.-J. Güntherodt, Appl. Phys. A: Mater. Sci. Process. 66, 55 (1998).

${ }^{11}$ H. F. Ji, K. M. Hansen, Z. Hu, and T. Thundat, Sens. Actuators B 72, 233 (2001).

${ }^{12}$ Y.-S. Lo, N. D. Heufner, W. S. Chan, P. Dryden, B. Hagenhoff, and T. P. Beebe, Jr., Langmuir 15, 6522 (1999). 